PROFESIONALES Y HERRAMIENTAS PARA EL DESARROLLO LOCAL Y SUS SINERGIAS TERRITORIALES. EVALUACIÓN Y PROPUESTAS DE FUTURO IX Coloquio Nacional de Desarrollo Local del GTDL-AGE 

ANTONIO MARTÍNEZ PUCHE, XAVIER AMAT MONTESINOS, ISABEL SANCHO CARBONELL y DANIEL SANCHIZ CASTAÑO (EDS.)

\section{PROFESIONALES Y HERRAMIENTAS PARA EL DESARROLLO LOCAL Y SUS SINERGIAS TERRITORIALES. EVALUACIÓN Y PROPUESTAS DE FUTURO}

IX Coloquio Nacional de Desarrollo Local del GTDL-AGE

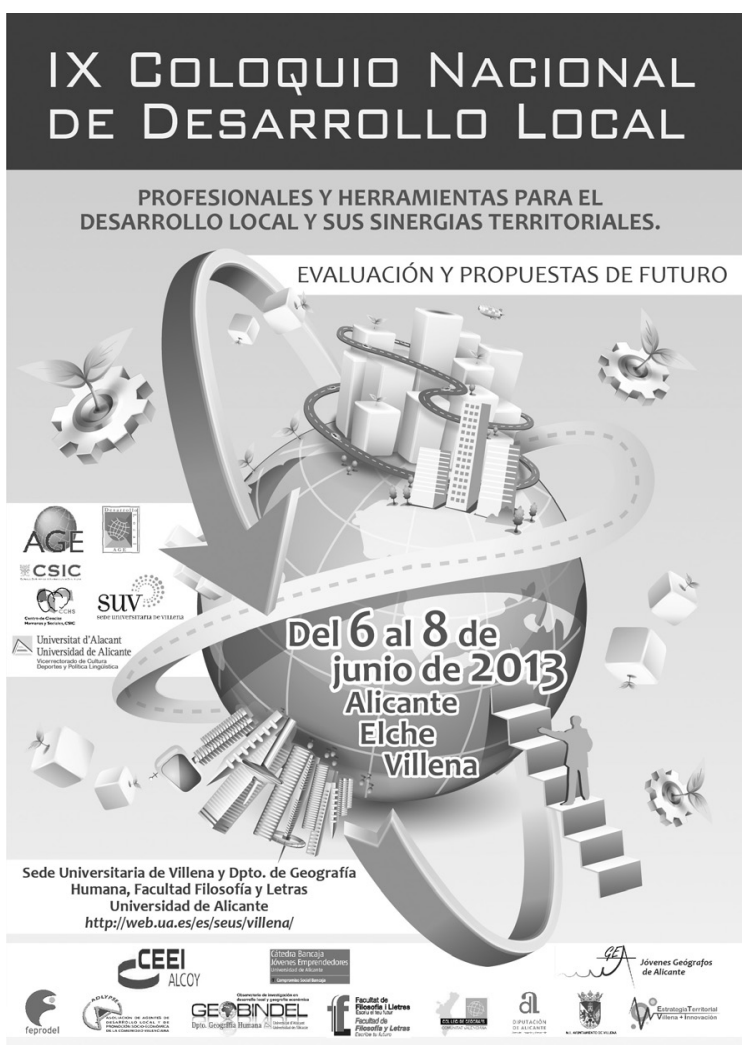


Este libro ha sido examinado y valorado por evaluadores ajenos a la Universidad de Alicante, con el fin de garantizar la calidad científica del mismo.

Publicacions de la Universitat d'Alacant

03690 Sant Vicent del Raspeig

Publicaciones@ua.es

http://publicaciones.ua.es

Telèfon: 965903480

(C) Antonio Martínez Puche, Xavier Amat Montesinos,

Isabel Sancho Carbonell y Daniel Sanchiz Castaño (eds.), 2016

(C) d'aquesta edició: Universitat d'Alacant

ISBN: 978-84-16724-00-0

Dipòsit legal: A 92-2016

Disseny de coberta: candela ink

Composició: Página Maestra (Miguel Ángel Sánchez Hernández)

Impressió i enquadernació: Guada Impresores

\section{unte \\ Unión de Editoriales
Universitarias Españolas \\ WWW.une.es
WWA}

Esta editorial es miembro de la UNE, cosa que garantiza la difusión y comercialización nacional y internacional de sus publicaciones.

Reservados todos los derechos. Cualquier forma de reproducción, distribución, comunicación pública o transformación de esta obra sólo puede ser realizada con la autorización de sus titulares, salvo excepción prevista por la ley. Diríjase a CEDRO (Centro Español de Derechos Repográficos, www.cedro.org) si necesita fotocopias o escanear algún fragmento de esta obra. 


\title{
PERSPECTIVA Y UTILIDAD DE LA PRÁCTICA DEL DESARROLLO LOCAL DESDE UN ENFOQUE INTEGRADO
}

\author{
Francisco Alburquerque Llorens \\ Ex funcionario de la ONU (ILPES y CEPAL) \\ Asesor del Banco Interamericano de Desarrollo \\ www.delalburquerque.com
}

\section{RESUMEN}

Los agentes y agencias de empleo y desarrollo local (AEDL) reaccionaron a la crisis de los años ochenta enfrentando desde sus propios ámbitos territoriales las exigencias de la reestructuración del tejido económico y social, desplegando para ello alianzas público-privadas encaminadas a fomentar el desarrollo local y el empleo, ocupando así espacios abandonados por la política económica del gobierno central.

De igual modo, ante la crisis actual y la falta de respuestas apropiadas por parte del gobierno central y la Unión Europea, los gobiernos locales, el sector privado empresarial en dichos territorios, asociaciones y grupos de la sociedad civil, y el sector de conocimiento (esto es, universidades, centros de asistencia tecnológica y de $\mathrm{I}+\mathrm{D}+\mathrm{i}$, organismos de formación profesional y técnica, entre otros) deberían ser capaces de concretar estrategias de desarrollo económico local y empleo al tiempo que alientan plataformas electorales ciudadanas en defensa de estos objetivos.

Palabras clave: Desarrollo Local. Crisis industrial. Crisis financiera. Iniciativas locales de empleo. Agentes de empleo y desarrollo local. Agencias de Desarrollo Local.

\section{PERSPECTIVE AND UTILITY OF THE PRACTICE OF THE ONE I DEVELOP LOCAL FROM AN INTEGRATED FOCUS}




\section{ABSTRACT}

The agents and employment agencies and local (AEDL) development reacted to the crisis of the years eighty facing from their territorial own environments the demands of the restructuring of the economic and social fabric, deploying for it public-private alliances guided to foment the local development and the employment, occupying this way spaces abandoned by the central government's economic politics.

In a same way, before the current crisis and the lack of appropriate answers on the part of the central government and European Union, the local governments, the managerial private sector in this territories, associations and groups of the civil society, and the sector of knowledge (this is, universities, centers of technological attendance and of $\mathrm{I}+\mathrm{D}+\mathrm{i}$, organisms of professional and technical formation, among other) should be able to sum up strategies of economic local development and employment at the time that you/they encourage platforms electoral citizens in defense of these objectives.

Key words: Develop Local, financial crisis, local initiatives of employment, employment agents and local development.

\section{El CONTEXTO DE LA CRISIS ACTUAL Y SU RELACIÓN CON LAS TAREAS PENDIENTES DE LA REESTRUCTURACIÓN ECONÓMICA Y POLÍTICA EN ESPAÑA}

Las situaciones de crisis evidencian los límites de los mecanismos de desarrollo existentes en un periodo histórico determinado. Las crisis muestran diversas facetas: de un lado, se aprecia que las instituciones existentes no logran asegurar la reproducción de los mecanismos de funcionamiento de la economía y la sociedad. Es lo que llamamos "crisis de regulación". De otro lado, las crisis suelen coincidir con momentos en los cuales está en cuestión el rumbo que debe tomar el desarrollo tecnológico, productivo y energético, lo cual está influido poderosamente por factores sociales, políticos e ideológicos.

Se trata de situaciones en las que viejas ideas surgidas de otros momentos históricos dificultan la difusión de las nuevas interpretaciones que conlleva una reflexión más detenida de los cambios a los que venimos asistiendo en las últimas décadas. Hay también factores políticos de naturaleza conservadora que hacen de freno a la introducción de las innovaciones sociales e institucionales. En la situación actual en España ello es debido a la fuerte relación (o imbricación) de estos factores políticos hegemónicos con los intereses económicos de los grandes grupos de poder que perpetúan las instituciones caducas y las reglas de una democracia devaluada a su mera expresión formalista o representativa, controlada -hasta hoy- por un bipartidismo surgido de la ley electoral impuesta en el proceso de transacción política que, conducido esencialmente por los viejos poderes fácticos del franquismo, llevó a la Constitución de 1978. 
En su célebre trabajo sobre La Segunda Ruptura Industrial, Michel Piore y Charles Sabel (1984) señalaban que la crisis económica desplegada desde los años setenta en las economías avanzadas ponía el énfasis principal en los límites del modelo de desarrollo industrial basado en la producción en serie, esto es, con utilización de maquinaria especializada y recursos humanos semicualificados para producir bienes y servicios estandarizados. Hasta cierto punto, en buena parte del sistema productivo actual en España, en especial, en lo relativo al grado de cualificación de los recursos humanos, se advierte la necesidad de una actuación en profundidad pensada de forma colectiva pero, fundamentalmente, teniendo en cuenta la participación de los diferentes ámbitos territoriales, ya que resulta obvio que los distintos mercados locales de empleo requieren recursos humanos con cualificaciones y aptitudes específicas además de cualificaciones básicas y genéricas o de carácter transversal, lo que dudosamente proporciona el deteriorado sistema educativo actual.

Según Piore y Sabel (1984), la crisis económica abierta en los años setenta mostraba la necesidad de: (i) una modificación o sustitución de las tecnologías y procedimientos operativos de las empresas y organizaciones en general; (ii) un cambio en los tipos de control del mercado de trabajo defendidos por los sindicatos; (iii) la revisión de los instrumentos de control macroeconómico desplegados por la burocracia en el poder; y (iv) cambios sustantivos en las reglas del sistema monetario internacional y comercial establecidos tras el término de la Segunda Guerra Mundial. De este modo, para enfrentar la crisis actual en España se requiere también tener en cuenta las tareas pendientes de la fase de transición o cambio estructural abierta desde aquellos años y que han sido eludidas hasta ahora, por unas circunstancias u otras.

Pero a pesar de la falta de una inteligente conducción económica de conjunto, en la segunda mitad de la década de 1980, las actuaciones de los/as AEDL mediante iniciativas locales de empleo e iniciativas de desarrollo económico local constituyeron una respuesta a la importante crisis de aquellos años, que implicaba la reestructuración de sectores productivos que hasta ese momento habían liderado el proceso de producción en serie y que se vieron cuestionados por la emergencia de un nuevo paradigma tecno-económico y energético basado en diferentes principios y formas organizativas de producción, con la presencia como factor clave de las nuevas tecnologías de la información y las comunicaciones, a lo que se suma el importante reto de la sostenibilidad ambiental de los procesos de producción y consumo.

Sin embargo, como he sugerido, la adaptación a las nuevas exigencias de este importante cambio estructural se fue demorando de forma casi permanente hasta el punto que aún hoy continuamos con una buena parte pendiente de la agenda de esta larga fase de adaptación tecnológica, energética, organizativa e institucional, cuando nos ha sorprendido la crisis actual, la cual no es solamente 
una crisis financiera, sino que detrás de la misma encontramos una crisis de reestructuración industrial del modelo productivo y de consumo.

En aquellos años ochenta, sectores como la siderurgia básica, la minería del carbón, y la construcción naval, entre otros, enfrentaban la presencia de nuevos competidores internacionales con salarios mucho más bajos y con esquemas de protección de su industria nacional emergente bastante más sólidos, junto a las crecientes exigencias de sostenibilidad ambiental en el uso de los recursos naturales y energéticos, en especial de los combustibles fósiles, cuya era comenzaba a declinar pese al no reconocimiento de este hecho por parte de los grandes intereses creados en torno a la industria del petróleo, el transporte y la automoción, con grandes vinculaciones con los respectivos gobiernos nacionales en las principales potencias.

Las respuestas de parte de la política económica se centraron entonces, principalmente, en la reestructuración industrial de sectores altamente contaminantes (minería del carbón, construcción naval, siderurgia, industria química, industria automovilística, entre otros) que se veían cuestionados por la mayor competitividad de los nuevos países industrializados del Este Asiático. Asimismo, en aquellos años, desde los diferentes ámbitos territoriales, se asistió al despliegue de iniciativas de desarrollo económico local y empleo ante el abandono que el gobierno central realizó al abrazar la tesis neoliberal de que "la mejor política industrial es la que no existe" territoriales y a los AEDL a incursionar en los ámbitos de la política empresarial, las políticas activas de empleo y, posteriormente, las políticas territoriales de innovación, con el fin de enfrentar el creciente desempleo y las dificultades del tejido de microempresas, pequeñas y medianas empresas y cooperativas de producción ante los retos de la incorporación a la Unión Europea.

Conviene también recordar que desde aquellos años ochenta en adelante, actividades estratégicas importantes que eran propiedad pública (como la telefonía, la banca, la electricidad, el agua potable, la distribución del petróleo, entre otras) fueron entregadas unilateralmente a monopolios privados, los cuales obtienen desde entonces enormes beneficios de ello, parte de los cuales se encuentran situados en paraísos fiscales, al tiempo que el Estado vio reducida su capacidad de disponer de ingresos públicos. Adicionalmente, se instauró la práctica de la reducción de impuestos a las grandes sociedades, se eliminó el impuesto sobre el patrimonio y el impuesto de sucesiones y transmisiones patrimoniales, y se profundizó en una desregulación financiera que permite la evasión de capitales hacia paraísos fiscales. Todo ello ha incidido poderosamen-

1 Fue el entonces Ministro de Industria, Claudio Aranzadi, del equipo del Ministro de Economía, Carlos Solchaga, quien hizo dicha afirmación a mediados de los ochenta, al tiempo que éste último señalaba que "España era el país donde más fácilmente se podía hacer dinero". Esto muestra la penetración de los planteamientos neoliberales y rentistas en esferas decisivas de aquel gobierno del PSOE de Felipe González. 
te en un mayor déficit público ante la incapacidad para incrementar los ingresos por parte del Estado.

Por si fuera poco, el mantenimiento de una ley del suelo que permite la obtención de ganancias extraordinarias de carácter especulativo mediante la recalificación de terrenos y el desprecio a los criterios de sostenibilidad medioambiental, agudizó las características del tipo de capitalismo rentista español que el ministro Solchaga ensalzaba, introduciendo de paso en las administraciones locales un espacio propenso a los comportamientos corruptos, ante el limitado avance de la descentralización de recursos y competencias a las administraciones municipales.

En los momentos actuales, la política económica se encuentra constreñida por un recetario de austeridad y ajuste impuesto desde las propias reglas de la Unión Europea, al tiempo que el gobierno central ha puesto bajo sospecha a los gobiernos locales y autonómicos, en un contexto en el cual las restricciones para el acceso al crédito por parte de las microempresas y pequeñas y medianas empresas dificulta cualquier recuperación del dinamismo económico y la creación de empleo.

Hay que insistir, contrariamente al pensamiento centralista predominante en el gobierno del Estado, que la descentralización y la mayor autonomía a nivel regional y municipal constituyen un planteamiento que puede enfrentar de forma más eficaz y eficiente las diferentes circunstancias de la crisis actual, a través de todo el instrumental de iniciativas de desarrollo local y empleo que en estos años atrás se han ido perfeccionando en la práctica. Sin embargo, las posiciones ideológicas del gobierno central retrasan un conjunto de reformas sustantivas que podría facilitar la búsqueda de un nuevo marco de competencias distribuidas entre los distintos niveles de la administración pública, en una superación del Estado de las Autonomías hacia un diseño más federativo, eficaz y solidario.

Como sabemos, la centralización de los poderes territoriales y el regreso al centralismo administrativo fue un camino que marcó el gobierno de la Sra. Thatcher ante la crisis económica de finales de los años setenta. Ahora es también el camino elegido por el gobierno conservador en España, a pesar de los importantes logros alcanzados por las iniciativas locales y regionales de desarrollo en las últimas décadas, cuyo reconocimiento es muy marginal en las simplificaciones que se realizan en el discurso económico y político predominante basado en la evolución macroeconómica y financiera. En estas simplificaciones desempeña un lugar central el antagonismo que se postula entre las nociones de Estado y mercado, lo cual merece alguna aclaración.

\section{ESTADO Y MERCADO, UN ANTAGONISMO MÁS IDEOLÓGICO QUE REAL}

Cuando en los albores del capitalismo británico del siglo XIX la nueva clase ascendente, esto es, la burguesía industrial, tuvo que enfrentar los privile- 
gios de la Corona, la Nobleza y la Iglesia, con el fin de ampliar sus horizontes de mercado, se construyó una contradicción básica que enfrenta las nociones de Estado y mercado, un antagonismo que ideológicamente sigue aún vivo en nuestros días. Las posiciones extremas eran, de un lado, el liberalismo manchesteriano del siglo XIX, defensor de un Estado mínimo a fin de permitir el funcionamiento del libre mercado; de otro lado, se encontraba el ejercicio jerárquico de la autoridad política desde las diferentes instancias del Estado Absoluto. Desde entonces, se propagó la creencia en una autorregulación automática de los mercados que, tras un falso concepto de libertad, considera al Sector Público como sinónimo de ineficiencia y autoritarismo.

Sin embargo, la idea de que los mercados funcionan mejor sin intervención estatal es errónea. Los mercados siempre funcionan en un contexto de reglas e instituciones, y no pueden desplegar su actividad sin la existencia de infraestructuras, reglas, bienes públicos y otras importantes condiciones del entorno territorial. Así, por ejemplo, la actividad comercial requiere infraestructuras de transporte, logística, comunicaciones, así como recursos humanos cualificados y condiciones de seguridad para hacer cumplir las leyes y reglas que hacen posible el comercio.

Las instituciones que apoyan a los mercados están diseñadas para reducir lo que los economistas llaman "costes de transacción”, esto es, los costes que involucran dichas actividades. La creación de instituciones formales para la regulación de los mercados incluye entre otros aspectos sustantivos: (i) los sistemas impositivos que permiten obtener recursos financieros para asegurar la dotación de bienes públicos (infraestructura, sanidad, educación, etc.); (ii) los regímenes legales para la administración de justicia y tribunales que posibiliten el cumplimiento de los contratos; y (iii) bancos centrales que garanticen la actividad económica y el empleo en condiciones de regulación y estabilidad financiera.

De este modo, la presencia del Sector Público es muy importante en las economías avanzadas. Los países desarrollados poseen mercados que funcionan mejor porque las administraciones públicas tienen una mayor presencia en comparación con los países menos desarrollados. Hoy día, en la Unión Europea el gasto público es, en promedio, el $47 \%$ del Producto Interior Bruto, aunque hay países que exceden ese promedio como Suecia (55\%), Francia $(52,7 \%)$ y Dinamarca (51\%), mientras otros países están por debajo del mismo, como España, Grecia y Portugal.

Según señala Dani Rodrik en su libro sobre La paradoja de la globalización. Democracia y futuro de la economía mundial (2011), una de las razones del aumento del gasto público en las décadas posteriores a 1945 ha sido la apertura del comercio internacional. Existe, pues, una correlación positiva entre volumen de comercio internacional y tamaño del Sector Público. Algunos países grandes (como EEUU), o más protegidos de forma natural frente a otros 
competidores (como Japón o Australia), muestran un crecimiento porcentual del gasto público menor que otras economías pequeñas o próximas a sus socios comerciales (como Suecia y los Países Bajos), que poseen un porcentaje superior de gasto público sobre el producto. En Suecia y los Países Bajos este porcentaje se sitúa entre el 55 y el 60\%, mientras que EEUU, Japón y Australia tienen porcentajes inferiores al $35 \%$

La expansión de los mercados exige, por tanto, una ampliación del Sector Público. Esta ampliación no se debe sólo a la necesidad de garantizar la seguridad, la salud, la justicia, la formación de los recursos humanos, el cumplimiento de los contratos o la gestión de la macroeconomía. Se debe también a la necesidad de proteger a la ciudadanía de los riesgos e inseguridad propios del funcionamiento de "los mercados". El Estado del Bienestar se levantó, pues, a medida que se ampliaban las relaciones en una economía abierta. Defender hoy el recorte del gasto público y del Estado del Bienestar no es solo una imposición autoritaria, es una pretensión que parece no aprender de las enseñanzas de la historia.

Es preciso entender, además, tal como insiste Rodrik (2011) que si bien los Estados nacionales son indispensables para garantizar el funcionamiento de los mercados nacionales, al mismo tiempo constituyen un obstáculo para el establecimiento de los mercados globales. La falta de un marco institucional global para los mercados internacionales y las tensiones que dichos mercados provocan entre instituciones locales son aspectos fundamentales para comprender el alcance y límites de la globalización económica actual. En realidad, las formulaciones fundamentalistas en favor de la autorregulación de los mercados tratan de minimizar la influencia de los Estados nacionales y dominar sus instituciones a fin de ponerlas al servicio de los principales grupos económicos.

La crisis en el Sur de Europa muestra la creciente subordinación de las políticas gubernamentales a los intereses de las grandes corporaciones y las fracciones financieras del capitalismo global. Corresponde a las sociedades democráticas, a través del sistema politico, mediante plataformas electorales conjuntas, tratar de enfrentar esta situación, superar las limitaciones de la democracia controlada por los grandes partidos, y orientar el uso del excedente económico hacia aplicaciones productivas y de empleo sostenibles, regulando y limitando la especulación financiera, y retirando de posiciones de responsabilidad pública a los fundamentalistas de los mercados.

\section{LA GLOBALIZACIÓN, LA COMPETITIVIDAD, LAS EXPORTACIONES Y EL CRECIMIENTO ECONÓMICO}

En el discurso económico predominante existen hoy día algunos términos reiteradamente utilizados como son los de competitividad, globalización, exportaciones y crecimiento, que parecen concitar un acuerdo bastante extendido a la 
hora de señalar las políticas que deben alentarse para encarar la crisis. Sin embargo, por lo general, una vez aludidos dichos términos, apenas se profundiza en las políticas que deben llevarse a cabo, quedando así como formulaciones de carácter genérico. Pero hay mucho que reflexionar sobre estos términos, sobre todo desde la perspectiva del desarrollo económico local.

El hecho de que estemos en economías más globalizadas no supone que todas las actividades de dichas economías estén orientadas hacia un "mercado globalizado". En realidad, una parte muy importante de las actividades económicas de cualquier país tiene como destino el mercado interno. Según datos del Banco Mundial, la parte que representan las exportaciones de bienes y servicios en el Producto Interior Bruto mundial es aproximadamente el $30 \%$ en el año 2010, un porcentaje bastante similar al que se ha venido manteniendo desde hace años. Esto quiere decir, que casi el $70 \%$ de la actividad productiva mundial no tiene como destino final el "mercado global", tratándose de actividades económicas básicamente locales. Esto sin considerar las actividades para el autoconsumo o las actividades de carácter informal.

Así pues, la producción para el mercado interno (o producción local) no es una parte menor de la economía. Más bien al contrario, es una parte sustantiva de la misma. Entre estas actividades hay que citar la actividad desplegada en los mercados municipales o en los mercados que tienen lugar en las diferentes ciudades, pueblos y comarcas; las actividades del comercio local; los servicios sociales (salud, educación, sanidad, entre otros); los transportes locales; los servicios personales (peluquerías, servicio doméstico, entre otros); guarderías; servicios de seguridad; actividades de ocio, cultura y deporte; urbanismo y vivienda, etc. Se trata de un grupo importante de actividades protagonizadas por microempresas, autónomos, pequeñas y medianas empresas y cooperativas, que constituyen un grupo protagonista principal del dinamismo económico local y el empleo en cualquier territorio.

Las economías no son conjuntos homogéneos. Y cuando se exagera el discurso globalizador y la competitividad de las llamadas "cadenas de valor globales", se está dejando de lado una parte importante de la economía. Precisamente aquella en la cual las microempresas y pequeñas y medianas empresas tienen mayor presencia, sin que sean tenidas en cuenta en ese discurso "excluyente" que limita la necesidad de mejora de la eficiencia productiva y la competitividad a las empresas grandes y medianas con destino exportador, en la presunción de que ello explica la totalidad del tejido productivo. Por eso es necesario insistir en la importancia de las economías locales y el mercado interno, sobre todo porque de ellas depende en gran parte el empleo y la cohesión económica y social de los municipios y comarcas.

No se cuestiona la necesidad de las exportaciones y el aumento de la competitividad en ese sector. Lo que se echa de menos es un enfoque territorial del desarrollo que incluya igualmente la mejora de la organización 
productiva y empresarial en las diferentes economías locales, una función en la cual las Agencias de Empleo y Desarrollo Local son instrumentos tan importantes como, a menudo, despreciados en ese discurso excluyente de la globalización.

El interés principal del gobierno del Estado español, tanto el gobierno anterior como el actual, parece estar del lado de los grandes empresarios y financieros. Pero es sabido que la política de fomento empresarial y productivo, así como las políticas activas de empleo dependen fundamentalmente de una actuación inteligente desde los gobiernos territoriales, lo cual requiere una eficiente coordinación interinstitucional entre los diferentes niveles de las administraciones públicas, lo que no siempre se da, mostrándose en ocasiones la indeseable reproducción del centralismo por parte de las instancias regionales (autonómicas) hacia las administraciones de menor nivel. Por lo demás, tampoco está claro que los gobiernos autonómicos tengan siempre una idea clara de su responsabilidad en el fortalecimiento del mercado interno y el empleo como estrategia de cohesión social, económica y territorial.

Hay que insistir en que la mejora de la competitividad no es sólo una cuestión que pueda ser tratada desde el nivel macroeconómico. No se trata únicamente, como se plantea desde la lógica cortoplacista de la patronal empresarial, de medidas de contención salarial y reducción de las aportaciones empresariales a la Seguridad Social o a la Hacienda Pública. En una fase de crisis y reestructuración productiva como la actual es fundamental el nivel microeconómico, a fin de garantizar la incorporación de innovaciones tecnológicas, medioambientales, organizativas, sociales e institucionales en la actividad productiva y el tejido empresarial, desde los diferentes ámbitos territoriales.

Esto supone que para lograr incorporar mejoras en la organización productiva y la competitividad se requiere fundamentalmente un enfoque de desarrollo territorial, ya que sólo desde cada ámbito local es posible llevar adelante los necesarios acuerdos y establecimiento de alianzas entre los actores públicos y privados, a fin de crear condiciones o entornos territoriales favorables a la incorporación de innovaciones productivas, organizativas, medioambientales, sociales e institucionales. Sólo con ese esfuerzo interno se puede sustentar, además, un dinamismo exportador duradero. La competitividad es, pues, sistémica, e involucra a todos los actores productivos, sociales, institucionales, financieros y del sector de conocimiento. Por tanto, además de los niveles "macro" y "micro" importan también los niveles "meso" (o de intermediación socioeconómica e institucional) y el nivel "meta", que alude al establecimiento de una visión estratégica territorial y el fomento de los valores y cultura adecuados para sustentar el proceso de desarrollo económico local (ver Gráfico 1). 


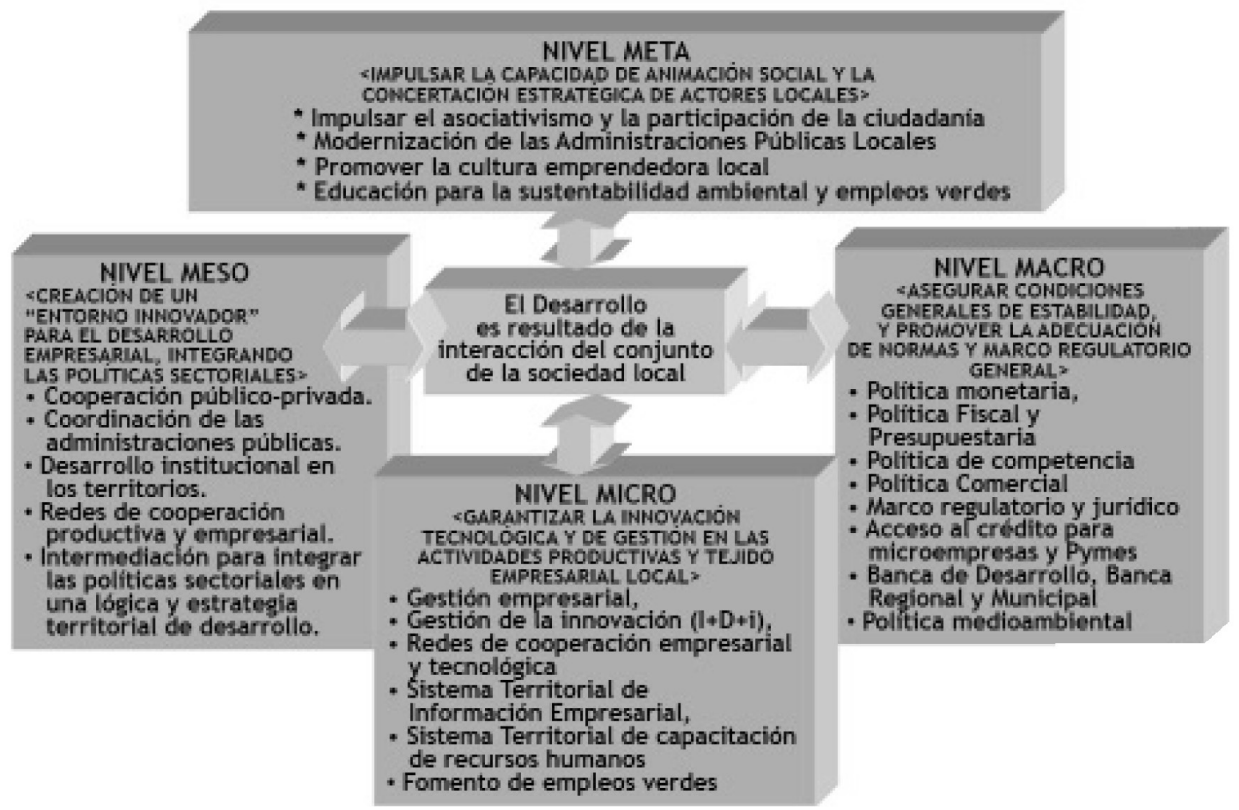

Gráfico 1. Niveles de la competitividad Sistémica

Fuente: A partir de Esser, Hilebrand, Messner y Meyer. Revista CEPAL, nº 59 (1996)

Finalmente, la diferencia entre crecimiento económico y desarrollo es un viejo y conocido debate. El desarrollo no puede limitarse a un mero crecimiento económico, ya que requiere incorporar la forma como se distribuye dicho crecimiento, esto es, incluye la forma de distribución del ingreso, y exige -además- conocer qué tipo de bienes y servicios componen dicho crecimiento. No es lo mismo producir armamento que proporcionar servicios educativos u otros servicios sociales. Igualmente, no es posible seguir insistiendo en un tipo de crecimiento económico insostenible ambientalmente. Así pues, cuando se habla de "recuperar el crecimiento", ¿de qué tipo de crecimiento económico se está hablando? ¿Acaso al tipo de crecimiento económico anterior basado en operaciones especulativas? Es obvio que se requiere avanzar en la incorporación de innovaciones sostenibles en la base económica existente, lo cual obliga a fortalecer las competencias de los diferentes actores territoriales.

No es solamente el crecimiento económico insostenible actual el que debe buscarse. Es preciso incorporar un tipo de desarrollo sostenible desde el punto de vista social, económico y ambiental. La apuesta por mejorar y cambiar las formas de producción insostenibles es una estrategia territorial más eficiente y competitiva hacia el futuro. Pero ello obliga a fortalecer los sistemas locales de innovación, esto es, los acuerdos entre los diferentes actores participantes en la aplicación de dichas innovaciones en los sistemas productivos locales. Estas 
cosas solo se hacen bien desde los diferentes ámbitos territoriales. Por eso es desafortunado un discurso excluyente de lo local, basado sólo en términos cuyo marketing los ha situado como si fueran incuestionables cuando en realidad son discursos llenos de ideología, consciente o inconscientemente asumida.

\section{UN VISTAZO AL FUTURO: ANTE UNA NUEVA RUPTURA INDUSTRIAL}

Según Jeremy Rifkin (La Tercera Revolución Industrial, 2011), la brusca subida de los precios del petróleo en la primera década del siglo XXI (desde 24 dólares/barril en 2001 a 147 dólares/barril en 2008), marcó el inicio del fin de la era de los combustibles fósiles. Dicha subida se trasladó al resto de los artículos básicos en los cuales el petróleo es un insumo estratégico. En efecto, el petróleo forma parte de los insumos básicos de numerosas cadenas de valor como la industria química y petroquímica (fertilizantes, pesticidas, plásticos, etc.), la industria de la construcción, la industria del cemento, la producción agraria y la producción de alimentos, la industria del transporte y del automóvil, la industria farmacéutica, la industria textil, la industria eléctrica (calefacción, iluminación), la industria metalmecánica, etc. El petróleo es, por tanto, un insumo estratégico en la actual civilización dependiente de los combustibles fósiles. Además, en un mundo en el cual el $40 \%$ de la población humana vive con menos de dos dólares/día, las variaciones de los precios de los productos básicos implican riesgos muy elevados.

El colapso financiero de 2008 desencadenado en EEUU y extendido luego en la Unión Europea, vino a sumarse a esta situación de agotamiento del modelo energético basado en los combustibles fósiles. Para Rifkin, sin embargo, no se trata de fenómenos independientes. La burbuja financiera y el aumento del déficit público guardan relación con la decadencia de la era del petróleo. De modo que las políticas que siguen enfrentando la crisis actual como si sólo se tratara de un tema financiero, no están llegando a la verdadera raíz del problema. En 2008 se habían alcanzado ya los límites del tipo de crecimiento económico dependiente del petróleo y otros combustibles fósiles. Se trata del final de la Segunda Revolución Industrial y de la era del petróleo en la que se basó la misma. En ese sentido, parece claro que hay que cambiar el régimen energético y el modelo industrial actual. La crisis actual no es sólo una crisis financiera. Es también, una crisis industrial.

Según la Agencia Internacional de la Energía (AIE) el techo de la producción global de petróleo se produjo en 2006, al llegar a los 70 millones de barriles diarios. Según la AIE, para mantener la producción de petróleo a un ritmo constante próximo a esa cifra es necesario invertir la impresionante cifra de 8 billones de dólares durante los próximos 25 años, a fin de continuar bombeando el petróleo que queda en los pozos existentes y que resulta cada vez más difícil (y más caro) de extraer. Asimismo, habría que perforar los yacimientos de me- 
nor rendimiento o de peor crudo ya existentes, y realizar nuevas prospecciones, cada vez más complicadas, ya que el crudo recuperable del planeta es cada vez más escaso, llevando consigo -además- su extracción riesgos de contaminación ambiental mucho más elevados, como se mostró en el accidente ocurrido en el Golfo de México, en abril de 2010, debido a la explosión y derrumbe de la plataforma petrolera de la Compañía British Petroleun, a $80 \mathrm{~km}$ de la costa de Luisiana. Hay que recordar, además, que el techo del petróleo disponible por habitante (esto es, haciendo el supuesto de que todos pudieran consumir lo mismo) se registró bastantes años atrás, en 1979. Y es que, aunque desde ese momento ha habido nuevos descubrimientos de pozos petrolíferos, la población mundial ha crecido con mayor rapidez.

El importante crecimiento de las economías de los "países emergentes" (China, Brasil, India, Sudáfrica, entre otros) ha venido a incrementar, además, la presión de la demanda sobre las reservas de crudo existentes, impulsando el precio del petróleo al alza. Existe, pues, una relación entre el incremento de la producción económica y el aumento de los precios del petróleo. En el año 2010, según la AIE, el monto total de las importaciones de petróleo de los 34 países de la OCDE se elevó desde los 200.000 millones de dólares US al comienzo de ese año hasta los 790.000 millones al término del mismo. Los países en desarrollo vieron también encarecerse de forma importante sus importaciones de petróleo.

Todo esto supone que la tensión hacia el incremento del precio del petróleo, debido al elevado ritmo de crecimiento económico de los países emergentes, seguirá en estos próximos años, lo que impulsará un nuevo aumento de los precios de los demás bienes y servicios, agudizando el desplome del poder adquisitivo general y llevando a la economía mundial cerca del colapso. Cada nuevo esfuerzo por recuperar el crecimiento económico de la pasada década tenderá a detenerse debido a la subida del petróleo. Esta es la situación a la que Rifkin se refiere cuando habla del final de una era.

Las actividades especulativas en los mercados de futuro del petróleo y los alimentos han agudizado (y siguen agudizando) esta situación, aunque no son la explicación principal del problema. Además, esta presión que ejerce la creciente demanda agregada de petróleo sobre unas reservas menguantes se ve agravada por el aumento de la agitación política en Oriente Medio y Próximo. La contestación creciente de las generaciones más jóvenes a los regímenes autocráticos de esa parte del mundo puede acabar incidiendo en situaciones de inestabilidad política y aumentos del precio del crudo.

No cabe, pues, otra opción razonable que la de intensificar la búsqueda de otro sistema energético y modelo industrial, indagando las formas de ahorro de energía y materiales en los procesos productivos y productos, y retomando la apuesta por las energías renovables. Este es un escenario que, en mi opinión, las iniciativas de Desarrollo Económico Local y Empleo deben contemplar con 
la mayor atención ya que las energías renovables no exigen grandes instalaciones centralizadas de producción energética sino estrategias de abastecimiento territorial de energía, utilizando para ello las diversas modalidades de fuentes de energía renovable (solar, eólica, biomasa, entre otras).

Por otra parte, el acercamiento de los lugares de producción y consumo de bienes y servicios debe ser, igualmente, otro de los criterios a contemplar, a fin de reducir el importante impacto en $\mathrm{CO}_{2}$ que implica hoy día el transporte y el comercio a larga distancia. Tal como señala la Fundación para la Nueva Economía (www.stro-ca.org/es), en 2004 el Reino Unido importó de Alemania 1,5 millones de kilos de patatas, a la vez que exportó a Alemania igualmente 1,5 millones de kilos de patatas. Del mismo modo, importó de Francia 10,2 millones de kilos de leche y nata, y exportó a ese país 9,9 millones de kilos de leche y nata. En ese mismo año el Reino Unido importó 17,2 millones de kilos de galletas recubiertas de chocolate y exportó 17,6 millones de kilos del mismo tipo de galletas. Importó cerveza por valor de 310 millones de libras esterlinas y exportó cerveza por valor de 313 millones de libras esterlinas. El Reino Unido importó en 2004 hasta 44.000 toneladas de porciones de pollo deshuesado y congelado, a la vez que exportó 51.000 toneladas de ese mismo producto. Todos estos datos pueden ser buenos para el comercio internacional, pero no lo son necesariamente para las personas ni, desde luego, para el planeta (Jordi Pigem, 2009).

\section{Algunas CONCLUSIONES}

El liderazgo que las fracciones financieras del capital han logrado sobre el capital productivo (la llamada "economía real"), constituye el elemento explicativo más relevante de los mayores niveles de dificultad e incertidumbre existentes para las inversions productivas y generadoras de empleo. Estos temas no deben ser sólo parte de una discusión global, sino que deben ponerse en práctica desde lo local, esto es, desde los diferentes ámbitos territoriales, para lo cual es posible contar con la experiencia acumulada estos años atrás por quienes han venido trabajando en estos temas desde la actividad de animadores territoriales de iniciativas de empleo y desarrollo económico local.

Desde esta actividad como facilitadores/as de procesos de desarrollo territorial y empleo hemos aprendido que la construcción de capital social territorial o, dicho de otra forma, el desarrollo de redes e instituciones locales a partir de acuerdos entre los diferentes actores territoriales, es la base principal de las estrategias de desarrollo. Esto quiere decir que el trabajo de los/as AEDL tiene un componente de articulación institucional y política (que no partidaria) ya que estos son temas de territorio, y no solo vinculados a ideologías partidistas.

En las experiencias avanzadas de desarrollo territorial se señala que cualquier estrategia debe contar con la presencia del sector público territorial, el sector privado empresarial local, el sector de conocimiento y la sociedad civil 
(esto es, un "modelo de cuatro hélices"). Así pues, parece clara la necesidad de impulsar un ejercicio de articulación profesional a fin de dar respuestas desde abajo, con la participación de los diferentes actores, compartiendo elementos del diagnóstico y, sobre todo, propuestas consensuadas para una acción coordinada por el desarrollo sostenible y el empleo desde nuestros ámbitos territoriales. Creo que tenemos instrumentos para aumentar nuestra vinculación efectiva. Y es un camino que requiere, igualmente, de una buena estrategia de comunicación social y política.

Como sabemos, para el impulso de iniciativas de desarrollo económico local y empleo el principal punto de partida no es otro que el de lograr una movilización y participación activa de los actores locales relevantes en cada territorio. De igual modo, una sensibilización y conciencia mayor acerca de la importancia de las actividades en este campo exige ampliar nuestra capacidad de incidir en dicha movilización ciudadana. Es posible que el desarrollo económico local no sea únicamente el resultado del esfuerzo desplegado "desde abajo" y concertado por los actores locales a partir de un mejor aprovechamiento de los recursos endógenos y de las oportunidades de dinamismo exógeno existentes. Se requiere también un contexto amigable desde la concepción de las políticas del Estado central y regional (autonómico).

Llegar a crear esta coherencia de políticas multinivel es un aspecto fundamental hacia el futuro. El desarrollo económico local dependerá no sólo de lo que seamos capaces de organizar de forma colectiva en nuestros territorios. Requerirá también de otras políticas influyentes como la planificación regional y el ordenamiento territorial, la política medioambiental, la política fiscal, la regulación de los movimientos financieros de capital especulativo, el avance de la descentralización, y una nueva dimensión de la política e institucionalidad democrática que debería asegurar una participación efectiva de la ciudadanía en todos los niveles de representación pública.

BIBLIOGRAFÍA

ESSER, K; HILLEBRAND, W; MESSNER, D. y MEYER-STAMER, J. (1996): "Competitividad sistémica: nuevos desafíos para las empresas y la política", Revista de la Cepal, No. 59, Santiago de Chile, Agosto.

PÉREZ, C. (2004): Revoluciones tecnológicas y capital financiero, México, 2004.

PIGEM, J. (2009): Buena crisis. Hacia un mundo postmaterialista. Kairós, Barcelona.

PIORE, M. y CHARLES S. (1984): La segunda ruptura industrial. Alianza, Madrid.

RIFKIN, J.(2011): La Tercera Revolución Industrial. Paidós, Barcelona.

RODRIK, D. (2011): La paradoja de la globalización. Democracia y el futuro de la economía mundial. Antoni Bosch, Barcelona. 